\title{
To which non-physician health professionals do French general practitioners refer their patients to and what factors are associated with these referrals? Secondary analysis
} of the French national cross-sectional ECOGEN study

Matthieu Peurois', Matthieu Chopin', Gaëlle Texier-Legendre', Cécile Angoulvant', William Bellanger', Cyril Bègue ${ }^{1,2}$ and Aline Ramond-Roquin ${ }^{1,2,3^{*}}$ (i)

\begin{abstract}
Background: Multiprofessional practice is a key component in primary care. Examining general practitioner (GP) referral frequency to non-physician health professionals (NPHP) can provide information about how primary care is organised and works which is useful for policymakers. Our study aimed to describe French GP referral frequency to various NPHPs in France and identify associated factors.

Methods: This is an ancillary study to the observational, cross-sectional (ECOGEN) study conducted in 2011/2012 in France among 128 GPs. Data about consultations using the standardised International Classification of Primary Care (ICPC-2), and patient and GP characteristics were collected from 20,613 GP consultations. Referrals were identified through inductive and deductive approaches using ICPC-2 codes, keywords, and deep, open manual searches. Referral frequency was described overall and per NPHP. Patient, GP, and consultation-related factors associated with referral rates were described for the three most frequently identified NPHPs. To minimise potential sources of bias, this observational study followed the STROBE guidelines.

Results: French GPs referred $6.8 \%$ of patients to NPHPs, with physiotherapists, podiatrists, and nurses accounting for $85.2 \%$ of referrals. Older patients, retired patients, multiple health problems managed, and longer consultation durations were found to be associated with higher referral rates $(p<0.001)$. Specific trends were observed for nurse, physiotherapist, and podiatrist referrals. Women $(p<0.001)$ and regular patients $(p=0.002)$ were more likely to receive physiotherapy referrals while people with no professional activity were less likely $(p<0.001)$. Female GPs and those working in urban practices were more likely to issue a physiotherapy referral $(p<0.001)$, while GPs working in rural practices $(p<0.001)$ and those with higher annual consultation numbers $(p=0.002)$ were more likely to refer to a
\end{abstract}

\footnotetext{
*Correspondence: aline.ramond@univ-angers.fr

1 Département de médecine générale, Univ Angers, F-49000 Angers,

France

Full list of author information is available at the end of the article
}

(c) The Author(s) 2022. Open Access This article is licensed under a Creative Commons Attribution 4.0 International License, which permits use, sharing, adaptation, distribution and reproduction in any medium or format, as long as you give appropriate credit to the original author(s) and the source, provide a link to the Creative Commons licence, and indicate if changes were made. The images or other third party material in this article are included in the article's Creative Commons licence, unless indicated otherwise in a credit line to the material. If material is not included in the article's Creative Commons licence and your intended use is not permitted by statutory regulation or exceeds the permitted use, you will need to obtain permission directly from the copyright holder. To view a copy of this licence, visit http://creativecommons.org/licenses/by/4.0/. The Creative Commons Public Domain Dedication waiver (http://creativeco mmons.org/publicdomain/zero/1.0/) applies to the data made available in this article, unless otherwise stated in a credit line to the data. 
nurse. Working in multiprofessional centres appeared to have little impact on referral rates, being only slightly associated with podiatrist referrals $(p=0.003)$.

Conclusions: Referral frequency is more associated with patient characteristics and clinical situations than GP-related factors suggesting patients needing referral most are most often referred. Furthermore, the three NPHPs that GPs refer to the most are those for which a referral is required for reimbursement in France, suggesting that health system legislation and NPHP reimbursement are strong determinants for referrals.

Keywords: Primary care, Health workforce, General practice, Referral, Health care organisation, Management

\section{Background}

The increasing prevalence of chronic diseases, multimorbidity $[1,2]$, and widening health needs $[3,4]$ is creating challenges in primary care, causing it to continually expand and change. In the context of this changing role, well-organised primary care helps reduce costs, improves user satisfaction, population health outcomes and equity, and strengthens health system performance [5]. Considering this, numerous countries have initiated health system reforms built around restructuring primary care provision, integrating patient care pathways, and enhancing interprofessional collaborations [6-9].

General practitioners (GP) play a key role in most health care systems since they are often responsible for coordinating patient care pathways, including referrals to non-physician health professionals (NPHPs) [10] and both the primary and secondary care sector [11]. In some countries they act as gatekeepers with GP referral validating health insurance reimbursement for consultations with other health professionals, including some NPHPs.

GP referral to NPHPs is a key indicator for multiprofessional practice [12]. Examining GP referral frequency to different NPHPs, and factors associated with referrals, can provide information about how primary care is organised and works.

Despite growing interest in developing multiprofessional practice in primary care, literature about NPHP referrals in general practice is still very scarce, apart from studies on nurse referrals or referrals for specific chronic diseases [13-17]. This knowledge would be useful for policymakers and all those involved in planning for future healthcare workforce requirements and developing multiprofessional practice in primary care teams [12].

NPHP referrals in general practice probably differ depending on the health care system. Therefore, any data on this topic should be carefully interpreted according to the national context, before being compared with data from other countries when available. In France, as in many other health care systems, GPs, nurses, and pharmacists form the core of primary care, along with various other health professionals, such as dentists, physiotherapists, midwifes, or podiatrists [18, 19]. A 2009 paper described the French primary care system as a "professional non-hierarchical model", like Germany or Canada, characterised by low level territorial organisation, coexistence of different practice types (solo practices, mono- and multiprofessional groups, including GPs, specialists, and NPHPs) and mainly private practices. This description was compared with "professional hierarchical models", where GPs have a strong, long-standing, and more formal gatekeeping role (such as in the UK, Netherlands, Australia, or New-Zealand) or "normative hierarchical models", where primary care is legally defined and based on multiprofessional territorial organisations (such as in Catalonia in Spain, Finland, or Sweden) [20]. Since then, French health policies and professional leaders have supported implementing multiprofessional practice and organisations in primary care, resulting in approximately $15 \%$ of GPs practicing within interprofessional health care teams, and a majority being engaged in various forms of multiprofessional practice. Furthermore, in France, GP referrals validate health insurance reimbursement for consultations with some NPHPs such as physiotherapists, nurses, speech therapists or podiatrists, while no GP referral is required to see pharmacists, dentists or midwifes. Except for specific situations, care from dieticians, psychologists or osteopaths is not reimbursed and patients must cover the full cost.

Building on original, nationwide, practice-based observational data, this study aims to describe French GP referral frequency to various NPHPs and identify factors associated with referral rates.

\section{Methods \\ Study design}

This study is a secondary analysis of ECOGEN (Elements of Consultation in General practice), a multicentric, observational, cross-sectional, nationwide study, aimed at describing general practice consultations in France. The ECOGEN study design has been previously described [17]. To minimise potential sources of bias, this observational study followed the STrengthening the Reporting of OBservational studies in Epidemiology (STROBE) guidelines. 
All procedures performed in studies involving human participants were in accordance with the national research committee and with the 1964 Helsinki declaration and its later amendments or comparable ethical standards.

\section{Data collection}

The ECOGEN study was conducted between December 2011 and April 2012, with an initially expected sample size of 16,000 consultations. Fifty-four trainee GPs from 27 French medical schools were trained to use the second version of International Classification of Primary Care (ICPC-2) $[21,22]$ which is the standardised classification chosen by the World Health Organisation for primary care [23]. ICPC-2 classifies patient data and clinical activity in terms of reason(s) for consultation (why the patient consulted the GP), consultation result(s) (the diagnosis/ problems/health conditions managed during the consultation) and healthcare procedure(s) (any intervention, including referral, performed, or prescribed during the consultation). The trainees collected data from $128 \mathrm{GP}$ internship supervisors. They observed their GP supervisor 1 day/week and systematically collected data for all consultations conducted on that day.

Specifically, patient data included age, sex, new or known patient, and socio-occupational information.
Socio-occupational categories were manual workers (such as builders and joiners), employees (such as office workers), other professional activities (including farmers, craftspeople, retailers, and senior managers), no professional activity (indicating people with no active employment including unemployed people, students, children, stay-at-home parents etc. excluding retired people) and retired. GP data included age, sex, practice location (rural, semi-rural or urban based on the GP's self-reported subjective response), practice type (solo, mono-professional group, or multi-professional group) and annual practice volume (annual number of consultations). Consultation data included consultation duration, as well as reasons for consultation, consultation results and healthcare procedures using ICPC-2 codes supplemented by verbatim and a hierarchical structure (Fig. 1).

\section{Definition of non-physician health professionals (NPHP)}

In this study "non-physician health professionals" refer to any registered health professionals except for physicians.

\section{Data extraction}

Inductive and deductive approaches were used to identify GP consultations resulting in patient referral to NPHPs using codes, keywords, and a deep, open

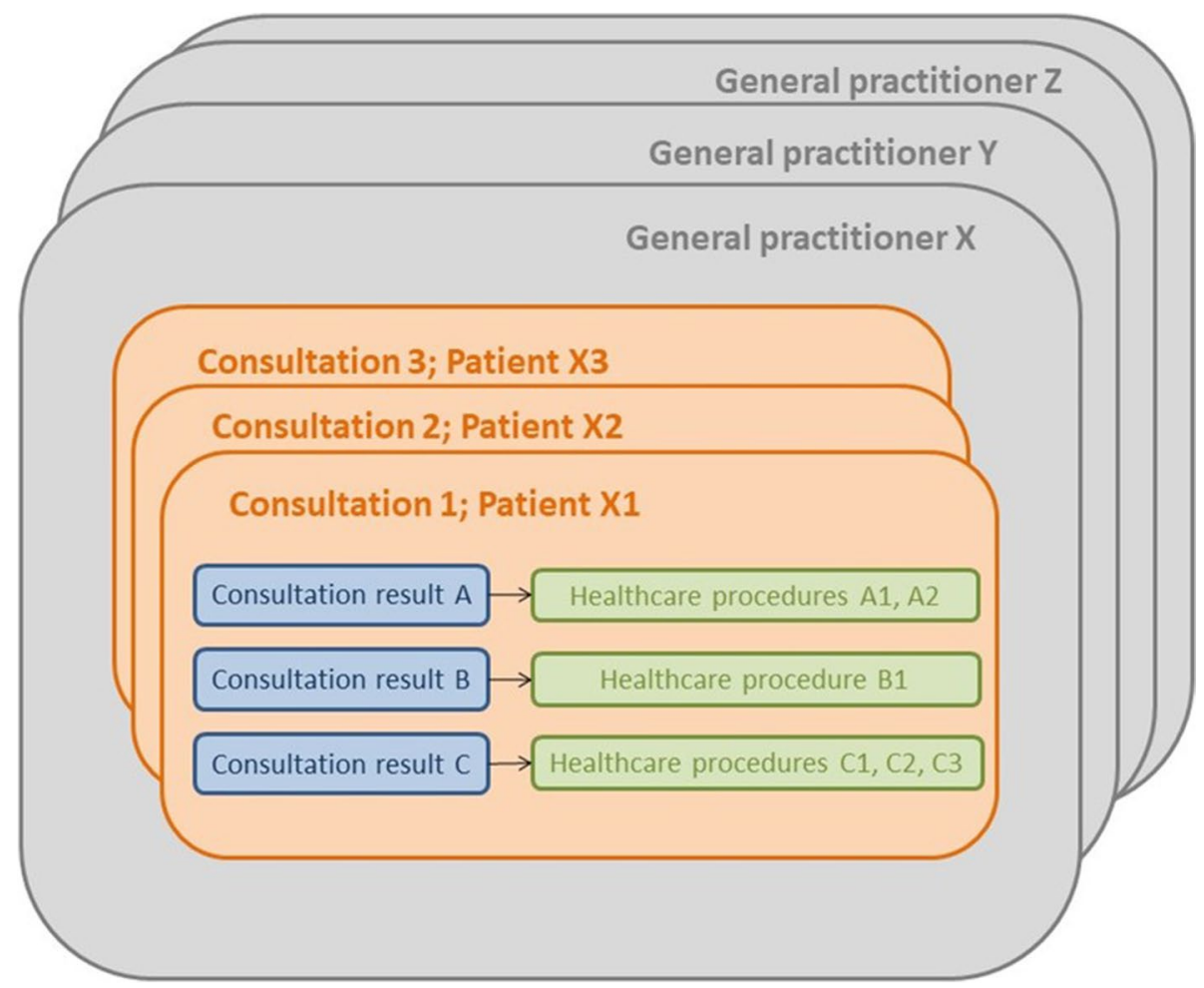

Fig. 1 Hierarchical structure of consultation data in ECOGEN study 
manual search. A list of NPHPs and related keywords were initially compiled (Table 1 ). ICPC- 2 codes relevant to our study were then identified. Codes -66 [referral to another health professional (excluding physicians)], and -68 [other referrals (not specified elsewhere)] were used in the automatic search strategy, while the code -67 [referral to physician/specialist/clinic/Hospital] was not. We also considered the code -57 [physiotherapy / rehabilitation] in relation with manual therapists. Finally, an Excel search with advanced filters was performed using the following 3 -step process.

- Step 1: Identify healthcare procedures coded -66 OR -68 in ICPC-2 (codes relating to referrals, except to a physician) with, then without, verbatim including at least one NPHP keyword. The observation (healthcare procedure and all related patient, GP, and consultation data) was automatically selected if verbatim included one or more NPHP keywords from our list. If verbatim did not include any NPHP keywords from our list, observations where referral to an NPHP was clearly stated in the verbatim were manually selected.

- Step 2: Identify healthcare procedures with any code other than -66 or -68 and verbatims including at least one NPHP keyword from our list. Only observations whose verbatim clearly related to a patient referral were manually selected.

- Step 3: Identify procedures coded -57 (code relating to manual therapy) and verbatims not including any of the NPHP keywords from our list. Only observations with verbatim clearly relating to referrals to physiotherapists or osteopaths (the two NPHPS using
The data extraction process was mainly conducted by the last author (ARR). In the case of automatic selection of observations (codes -66 or -68 AND presence of NPHP keywords in the verbatim), only ARR checked the selection appropriateness. In all the other cases (manual selection, when codes or keywords were absent) a double check (ARR with $\mathrm{CB}$ or CA) was undertaken.

\section{Data analysis}

Categorical variables were described as number (\%) and continuous variables were described as mean (SD). The referral frequency was described, both overall and per NPHP. Patient, GP, and consultation-related factors associated with referral rates were described for the three most frequently identified NPHPs, using univariate statistical analysis: chi- 2 tests in the case of categorical variables, and Student- $t$ tests in the case of continuous variables. Due to the study sample size and the multiple comparisons, only highly statistically significant associations ( $p$-values $<0.001$ ) have been highlighted. Analyses were performed using BiostaTGV.

\section{Results}

The ECOGEN database contains 20,613 consultations, 45,582 consultation results and 98,847 healthcare procedures.

\section{Patient, GP, and consultation characteristics}

The average patient age was 46.6 years, $58.2 \%$ were women, $32.8 \%$ were retired and $94.5 \%$ were regular patients. The average GP age was 53 years, $34.3 \%$ were women, $54.3 \%$ practiced in urban areas, and $79.9 \%$ were

Table 1 First list of NPHPs considered and related keywords

\begin{tabular}{|c|c|c|}
\hline Profession (English) & Profession (French) & Keywords (French) \\
\hline Nurses & Infirmiers/infirmières & «*infirmi* ${ }^{*}$ or «* ide* » \\
\hline Physiotherapists & Kinésithérapeutes/rééducation & «*kin*»or «* rééduc* » \\
\hline Psychologists & Psychologues & «"psychol* » and not « ${ }^{*}$ soutien* » \\
\hline Midwives & Sage-femmes & « ${ }^{*} \mathrm{sage}^{*} »$ or $«{ }^{*} \mathrm{sf}{ }^{*} »$ \\
\hline Dentists & Dentistes & «*dent*» \\
\hline Dieticians/nutritionists & Diététicienne/nutritionniste & «* diét* »or «*nutri* »or «*diététic* » \\
\hline Osteopaths & Ostéopathe/thérapie manuelle & «* ostéo* » or « *manuel* » or *manip* » \\
\hline Social workers & Assistantes sociales & «*assist* ${ }^{*}$ or « ${ }^{*}$ social* $»$ or « ${ }^{*} a s^{*} »$ \\
\hline Pharmacists & Pharmaciens & « pharma*» \\
\hline Podiatrists & Podologues/semelles & « "podo*» or « "pédic* » or « ${ }^{*}$ semel*» \\
\hline Speech therapists & Orthophonistes & «*orthoph*» \\
\hline Occupational therapists & Ergothérapeutes & «*ergot*» \\
\hline Psychomotor therapists & Psychomotricien-nes & « ${ }^{*}$ psychomot ${ }^{*} »$ \\
\hline
\end{tabular}

manual therapy in France) were manually selected.

in a mono-professional practice (either solo or group). 
The mean consultation duration was $16.7 \mathrm{~min}$, the average number of consultation results (health conditions managed) per consultation was 2.21 and the average number of healthcare procedures per consultation was 4.8 (Table 2).

GPs referred 1396 patients (6.8\%) to an NPHP (Table 3 ). The total number of referrals was 1455 reflecting the fact that some patients were referred to two or more NPHPs during the same consultation. Patients were mostly referred to physiotherapists $(4.5 \%)$, podiatrists $(0.8 \%)$ and nurses $(0.7 \%)$, accounting for $85.2 \%$ of referrals.
Table 3 Number of patients general practitioners referred to NPHPS

\begin{tabular}{lll}
\hline $\begin{array}{l}\text { Non-physician health } \\
\text { professional }\end{array}$ & $\begin{array}{l}\text { Number of referrals } \\
(\boldsymbol{n}=\mathbf{1 4 5 5 )}\end{array}$ & $\begin{array}{l}\text { \% of total } \\
\text { consultations }\end{array}$ \\
\hline Physiotherapists & $927(63.7 \%)$ & 4.5 \\
Podiatrists & $172(11.7 \%)$ & 0.8 \\
Nurses & $142(9.8 \%)$ & 0.7 \\
Psychologists & $49(3.4 \%)$ & 0.2 \\
Osteopaths & $36(2.5 \%)$ & 0.2 \\
Speech therapists & $29(2 \%)$ & 0.1 \\
Dentists & $28(1.9 \%)$ & 0.1 \\
Nutritionists & $27(1.9 \%)$ & 0.1 \\
Others &
\end{tabular}

${ }^{a}$ Others include social workers, orthoptists, midwives, etc.

Table 2 Patient, GP, and consultation characteristics in the ECOGEN dataset

Total $(n=20,613)$

\begin{tabular}{|c|c|}
\hline \multicolumn{2}{|l|}{ Patient Characteristics } \\
\hline Age: mean (SD) & $46.6(25.7)$ \\
\hline Female: number (\%) & $11,995(58.2)$ \\
\hline \multicolumn{2}{|l|}{ Socio-occupational category: number (\%) } \\
\hline Employee & $3972(19.3)$ \\
\hline Worker & $815(4.0)$ \\
\hline Other professional activity ${ }^{\mathrm{a}}$ & $2910(14.2)$ \\
\hline No professional activity ${ }^{\mathrm{b}}$ & $6150(29.8)$ \\
\hline Retired & $6766(32.8)$ \\
\hline Regular patients: number (\%) & $19,473(94.5)$ \\
\hline \multicolumn{2}{|l|}{ General practitioner characteristics } \\
\hline Age: mean (SD) & $53.0(7.5)$ \\
\hline Female: number (\%) & $7063(34.3)$ \\
\hline \multicolumn{2}{|l|}{ Location: number (\%) } \\
\hline Rural & $4163(20.2)$ \\
\hline Semi-rural & $5266(25.5)$ \\
\hline Urban & $11,184(54.3)$ \\
\hline \multicolumn{2}{|l|}{ Practice type: number (\%) } \\
\hline Solo & $4330(21.0)$ \\
\hline Mono-professional medical group & $12,149(58.9)$ \\
\hline Multiprofessional centres & $4134(20.1)$ \\
\hline Annual number of consultations: mean (SD) & $5162(1749)$ \\
\hline \multicolumn{2}{|l|}{ Consultation Characteristics } \\
\hline Mean duration: minutes (SD) & $16.7(8.3)$ \\
\hline Number of consultation results: mean (SD) & $2.21(1.44)$ \\
\hline \multicolumn{2}{|l|}{ Number of consultation results during the consultation } \\
\hline 1 consultation result: number (\%) & $8567(41.6)$ \\
\hline 2 consultation results: number (\%) & $5644(27.4)$ \\
\hline 3 consultation results: number (\%) & $3250(15.8)$ \\
\hline 4 consultation results: number (\%) & $1614(7.8)$ \\
\hline $5+$ consultation results: number (\%) & $1538(7.5)$ \\
\hline Healthcare procedures delivered per consultation: mean (SD) & $4.8(3.09)$ \\
\hline
\end{tabular}

ancludes professions such as farmers, retailers, craftspeople and senior managers

${ }^{b}$ Includes children, unemployed people, stay at home parents, students etc. but does not include retired people 
Referrals to physiotherapists, podiatrists, and nurses Table 4 highlights factors associated with referrals to physiotherapists, podiatrists, and nurses. In general, those who received a referral were older than those who did not. This was particularly true for nurse referrals, where the mean patient age was 70.3 (SD 20.7) years versus 46.4 (SD 25.7) years for those who did not receive a referral. Referrals to physiotherapists, podiatrists, and nurses were strongly associated with longer consultation durations. Consultations with physiotherapy referrals were an average of $2.4 \mathrm{~min}$ longer, podiatrists an average of $2.6 \mathrm{~min}$ longer and nurses an average of $3.8 \mathrm{~min}$ longer.

In addition, $47.2 \%$ of patients referred to a nurse had three or more consultation results compared with only $30.9 \%$ of patients not referred to a nurse. Similar significant differences were observed with referrals to physiotherapists ( $45.0 \%$ of referred patients have three or more consultation results versus $30.4 \%$ in those not referred) and podiatrists (52.3\% versus $30.9 \%)$ (See Fig. 2).

No significant $(p<0.001)$ associations were found between referrals to any of these three NPHPs and GP age.

\section{Physiotherapist referrals}

In addition to the previously described associations, women were more frequently referred to a physiotherapist, accounting for $65 \%$ of consultations resulting in a physiotherapy referral compared with $57.9 \%$ with no referral. Regular patients appear to be more often referred than non-regular patients, but this was only a non-significant trend $(p=0.002)$. When comparing people who received a physiotherapy referral and those who did not, people with no professional activity were less frequently referred to a physiotherapist than those in other socio-occupational categories (patients with no professional activity accounted for $20.6 \%$ of patients referred to a physiotherapist compared with $30.3 \%$ of those not referred). This association remained significant even after restriction to non-retired people. Female GPs were more likely to issue a physiotherapy referral (female GPs accounted for $42.5 \%$ of consultations with a physiotherapy referral, compared with $33.9 \%$ in consultations with no referral). Furthermore, urban practices account for $64.3 \%$ of consultations with a physiotherapist referral compared with $53.8 \%$ with no physiotherapist referral.

\section{Nurse referrals}

When comparing patients who received a nurse referral and those who did not, $70.4 \%$ of patients referred to a nurse were retired compared with just $32.6 \%$ of patients who were not referred. Rural practices appear to be more likely to refer to a nurse (accounting for $38 \%$ of consultations with a nurse referral compared with $20.1 \%$ with no nurse referral). Furthermore, even though nonsignificant, GPs with higher annual consultation numbers seemed to be associated with more nurse referrals (an average of 5619 consultations per year for GPs referring a patient to a nurse versus 5158 for those who did not, $p=0.002)$.

\section{Podiatrist referrals}

In addition to previously described associations that are common to all three NPHPs, only a non-significant $(p>0.001)$ trend was observed for podiatrists. GPs in multiprofessional centres appear more likely to refer to a podiatrist $(31.4 \%$ of GPs referring a patient to a podiatrist worked in a multiprofessional practice versus $20 \%$ of those who did not refer $(p=0.003))$.

\section{Discussion}

Our findings show that French GPs refer $6.8 \%$ of patients to NPHPs, with physiotherapists, podiatrists, and nurses accounting for $85.3 \%$ of referrals. We found higher referral rates are associated with older, retired patients, with multiple health problems, and longer consultation durations. Specific associations and trends were observed for referrals to nurses, physiotherapists, and podiatrists.

To our knowledge, no data are available from other countries that may be directly compared to ours in terms of referral rates. Publications concerning NPHP referrals mostly rely on declarative data, which are subject to different biases (such as memory or social desirability), rather than observational practice-based data, and do not report consultation-scale data that would allow GP referral rates to be estimated $[24,25]$.

In France, the health system requires a GP to prescribe physiotherapist, podiatrist, or nurse treatments which the national health insurance then reimburses. This would explain why GPs refer to these three NPHPs most often, at least explicitly, as opposed to a pharmacist, a midwife, or a dentist for whom formal referral is not needed. GPs in France prescribe medication to patients in $80.7 \%$ of consultations, making pharmacists possibly the most referred to profession [26], but this referral is not explicitly discussed with the patient. Importantly, the GP referral process does not cover visits to nutritionists, psychologists, or osteopaths, which the French national health insurance will not reimburse. Patients most often decide to consult these non-reimbursed professionals either upon GP advice or through a self-referral process explaining the lower formal referral rates to these NPHPs in our study.

In addition to the issue of reimbursement, there may be other barriers to patients consulting these non-reimbursed NPHPs. These barriers include NPHPs, such as psychologists and dieticians, often being less accessible 
Table 4 Patient, GP, and consultation-related factors associated with GP referral to physiotherapists, podiatrists, or nurses

\begin{tabular}{|c|c|c|c|c|c|c|c|c|c|}
\hline & \multicolumn{3}{|c|}{ Referrals to physiotherapists } & \multicolumn{3}{|c|}{ Referrals to podiatrists } & \multicolumn{3}{|l|}{ Referrals to nurses } \\
\hline & $\begin{array}{l}\text { Consultations } \\
\text { with referral to a } \\
\text { physiotherapist } \\
(n=927)\end{array}$ & $\begin{array}{l}\text { Consultations } \\
\text { without } \\
\text { referral to a } \\
\text { physiotherapist } \\
(n=19,686)\end{array}$ & $p$-value & $\begin{array}{l}\text { Consultations } \\
\text { with referral } \\
\text { to a podiatrist } \\
(n=172)\end{array}$ & $\begin{array}{l}\text { Consultations } \\
\text { without referral } \\
\text { to a podiatrist } \\
(n=20,441)\end{array}$ & $p$-value & $\begin{array}{l}\text { Consultations } \\
\text { with referral to a } \\
\text { nurse }(n=142)\end{array}$ & $\begin{array}{l}\text { Consultations } \\
\text { without referral } \\
\text { to a nurse } \\
(n=20,471)\end{array}$ & $p$-value \\
\hline \multicolumn{10}{|c|}{ Patient characteristics } \\
\hline Age: mean (SD) & $51.7(23.2)$ & $46.4(25.8)$ & $<0.001^{*}$ & $52.9(21.8)$ & $46.5(25.7)$ & $<0.001^{*}$ & $70.3(20.7)$ & $46.4(25.7)$ & $<0.001^{*}$ \\
\hline $\begin{array}{l}\text { Female: num- } \\
\text { ber (\%) }\end{array}$ & $603(65.0)$ & $11,392(57.9)$ & $<0.001^{*}$ & $101(58.7)$ & $11,894(58.2)$ & 0.89 & $90(63.4)$ & $11,905(58.2)$ & 0.21 \\
\hline $\begin{array}{l}\text { Socio-occupa- } \\
\text { tional category: } \\
\text { number (\%) }\end{array}$ & & & $<0.001^{*}$ & & & 0.03 & & & $<0.001^{*}$ \\
\hline Employee & $218(23.5)$ & $3754(19.1)$ & & $32(18.6)$ & $3940(19.3)$ & & $10(7.0)$ & $3962(19.4)$ & \\
\hline $\begin{array}{l}\text { Manual } \\
\text { worker }\end{array}$ & $47(5.1)$ & $768(3.9)$ & & $4(2.3)$ & $811(4.0)$ & & $5(3.5)$ & $810(4.0)$ & \\
\hline $\begin{array}{l}\text { Other pro- } \\
\text { fessional activity }\end{array}$ & $137(14.8)$ & $2773(14.1)$ & & $29(16.9)$ & $2881(14.1)$ & & $6(4.2)$ & $2904(14.3)$ & \\
\hline $\begin{array}{l}\text { No profes- } \\
\text { sional activity }^{\mathrm{b}}\end{array}$ & $191(20.6)$ & $5959(30.3)$ & & $37(21.5)$ & $6113(29.9)$ & & $21(14.8)$ & $6129(29.9)$ & \\
\hline Retired & $334(36.0)$ & $6432(32.7)$ & & $70(40.7)$ & $6696(32.8)$ & & $100(70.4)$ & $6666(32.6)$ & \\
\hline $\begin{array}{l}\text { Regular } \\
\text { patients: number } \\
\text { (\%) }\end{array}$ & $897(96.8)$ & $18,576(94.4)$ & 0.002 & $165(95.9)$ & $19,308(94.5)$ & 0.40 & $136(95.8)$ & $19,337(94.5)$ & 0.50 \\
\hline \multicolumn{10}{|l|}{ GP characteristics } \\
\hline Age: mean (SD) & $52.5(7.7)$ & $53.0(7.5)$ & 0.04 & $51.7(7.5)$ & $53.0(7.5)$ & 0.025 & $53.3(7.5)$ & $53.0(7.5)$ & 0.60 \\
\hline $\begin{array}{l}\text { Female: num- } \\
\text { ber (\%) }\end{array}$ & $394(42.5)$ & $6669(33.9)$ & $<0.001^{*}$ & $68(39.5)$ & $6995(34.2)$ & 0.14 & $41(28.9)$ & $7022(34.3)$ & 0.17 \\
\hline $\begin{array}{l}\text { Location: } \\
\text { number (\%) }\end{array}$ & & & $<0.001^{*}$ & & & 0.10 & & & $<0.001^{*}$ \\
\hline Rural & $159(17.2)$ & $4004(20.3)$ & & $33(19.2)$ & $4130(20.2)$ & & $54(38.0)$ & $4109(20.1)$ & \\
\hline Semi-rural & $172(18.6)$ & $5094(25.9)$ & & $33(19.2)$ & $5233(25.6)$ & & $27(19.0)$ & $5239(25.6)$ & \\
\hline Urban & $596(64.3)$ & $10,588(53.8)$ & & $106(61.6)$ & $11,078(54.2)$ & & $61(43.0)$ & $11,123(54.3)$ & \\
\hline $\begin{array}{l}\text { Practice type: } \\
\text { number (\%) }\end{array}$ & & & 0.46 & & & 0.003 & & & 0.01 \\
\hline Solo & $214(23.1)$ & $4116(20.9)$ & & $28(16.3)$ & $4302(21.0)$ & & $24(16.9)$ & $4306(21.0)$ & \\
\hline Group & $530(57.2)$ & $11,619(59.0)$ & & $90(52.3)$ & $12,059(59.0)$ & & $98(69.0)$ & $12,051(58.9)$ & \\
\hline $\begin{array}{l}\text { Multi-profes- } \\
\text { sional centre }\end{array}$ & $183(19.7)$ & $3951(20.1)$ & & $54(31.4)$ & $4083(20.0)$ & & $20(14.1)$ & $4114(20.1)$ & \\
\hline $\begin{array}{l}\text { Annual num- } \\
\text { ber of consulta- } \\
\text { tions: mean (SD) }\end{array}$ & $5071(1693)$ & $5166(1752)$ & 0.11 & $5004(1642)$ & $5163(1750)$ & 0.24 & $5619(1825)$ & $5158(1748)$ & 0.002 \\
\hline \multicolumn{10}{|c|}{ Consultation characteristics } \\
\hline $\begin{array}{l}\text { Mean duration: } \\
\text { minutes (SD) }\end{array}$ & $19.0(8.3)$ & $16.6(8.3)$ & $<0.001^{*}$ & $19.3(8.6)$ & $16.7(8.3)$ & $<0.001^{*}$ & $20.5(9.6)$ & $16.7(8.3)$ & $<0.001^{*}$ \\
\hline $\begin{array}{l}\text { Number of } \\
\text { consultation } \\
\text { results: mean (SD) }\end{array}$ & $2.74(1.73)$ & $2.16(1.42)$ & $<0.001^{*}$ & $2.92(1.53)$ & $2.18(1.44)$ & $<0.001^{*}$ & $2.76(1.8)$ & $2.18(1.44)$ & $<0.001^{*}$ \\
\hline $\begin{array}{l}\text { Number of } \\
\text { consultation } \\
\text { results: number } \\
\text { (\%) }\end{array}$ & & & $<0.001^{*}$ & & & $<0.001^{*}$ & & & $<0.001^{*}$ \\
\hline
\end{tabular}


Table 4 (continued)

\begin{tabular}{|c|c|c|c|c|c|c|c|c|c|}
\hline & \multicolumn{3}{|c|}{ Referrals to physiotherapists } & \multicolumn{3}{|c|}{ Referrals to podiatrists } & \multicolumn{3}{|l|}{ Referrals to nurses } \\
\hline & $\begin{array}{l}\text { Consultations } \\
\text { with referral to a } \\
\text { physiotherapist } \\
(n=927)\end{array}$ & $\begin{array}{l}\text { Consultations } \\
\text { without } \\
\text { referral to a } \\
\text { physiotherapist } \\
(n=19,686)\end{array}$ & $p$-value & $\begin{array}{l}\text { Consultations } \\
\text { with referral } \\
\text { to a podiatrist } \\
(n=172)\end{array}$ & $\begin{array}{l}\text { Consultations } \\
\text { without referral } \\
\text { to a podiatrist } \\
(n=20,441)\end{array}$ & $p$-value & $\begin{array}{l}\text { Consultations } \\
\text { with referral to a } \\
\text { nurse }(n=142)\end{array}$ & $\begin{array}{l}\text { Consultations } \\
\text { without referral } \\
\text { to a nurse } \\
(n=20,471)\end{array}$ & $p$-value \\
\hline $\begin{array}{l}1 \text { consulta- } \\
\text { tion result: } \\
\text { number }(\%)\end{array}$ & $252(27.2)$ & $8315(42.2)$ & & $24(14.0)$ & $8543(41.8)$ & & 34 (23.9) & $8533(41.7)$ & \\
\hline $\begin{array}{l}2 \text { consulta- } \\
\text { tion results: } \\
\text { number }(\%)\end{array}$ & $258(27.8)$ & $5386(27.4)$ & & $58(33.7)$ & $5586(27.3)$ & & $41(28.9)$ & $5603(27.4)$ & \\
\hline $\begin{array}{l}3 \text { consulta- } \\
\text { tion results: } \\
\text { number }(\%)\end{array}$ & $176(19.0)$ & 3074 (15.6) & & $42(24.4)$ & 3208 (15.7) & & $31(21.8)$ & 3219 (15.7) & \\
\hline $\begin{array}{l}4 \text { consulta- } \\
\text { tion results: } \\
\text { number }(\%)\end{array}$ & $102(11.0)$ & $1512(7.7)$ & & $23(13.4)$ & $1591(7.8)$ & & $22(15.5)$ & $1592(7.8)$ & \\
\hline $\begin{array}{l}5+\text { consulta- } \\
\text { tion results: } \\
\text { number }(\%)\end{array}$ & $139(15.0)$ & $1399(7.1)$ & & $25(14.5)$ & $1513(7.4)$ & & $14(9.9)$ & $1524(7.4)$ & \\
\hline
\end{tabular}

in comparison to other health professionals since they have shorter opening hours, rarely perform home visits and there are fewer of them meaning distribution is reduced [27]. Furthermore, acceptability may be an issue for some patients since there is still stigma surrounding eating or weight disorders and mental health problems and patients can find these disorders difficult to accept [28-31].

GPs and nurses often support patients presenting with mental health or eating disorders, since they commonly have expertise in these areas [32-35]. Some of these patients would also benefit from psychologist or dietician consultations [36, 37]. In France, patients with chronic diseases such as diabetes can also be supported by health professional teams including GPs and public health nurses, with interesting results for some intermediate outcomes (such as glycaemia and adherence to follow-up tests). However, morbidity and mortality results are still lacking $[38,39]$. Regardless of the team configuration, role clarification is essential to prevent conflicts between team members and implement effective interprofessional care [40, 41]. However, the implications of overlapping tasks for patients and health professionals remain largely unknown.

Importantly, not all patients need referring to an NPHP. GPs provide comprehensive and patient-centred care for many patients, alone or with other health professionals. They play an essential role aiming to ensure the limited available health care resources are allocated equitably to those who require further care. In this respect, we observed that increased age and multiple health problems managed were associated with high referral probability. This association has already been observed with GP referrals to dieticians and nutritionists in Australia [25] and is consistent with chronic condition and multimorbidity prevalence increasing with age $[42,43]$ and the increased need for multiprofessional care for these patients [44, 45]. In addition, we found consultation duration was longer ( $3 \mathrm{~min}$ on average) if a referral ensued. This may suggest that complex, comorbid patients require more referrals, or the extra duration may reflect the time needed to discuss the referral with the patient and write the referral letter.

Furthermore, the higher rate of physiotherapist referral in female patients has already been described in the literature [46]. The literature also reveals that female physicians have longer consultation durations, and are more likely to make follow-up arrangements and referrals and perform female prevention procedures [47]. This could partly be explained by physician-patient gender concordance [47].

GPs not actively creating networks with local NPHPs [48] or GPs and NPHPs not working together in multiprofessional centres [49] have been previously suggested as potential barriers to multiprofessional practice. In our study, co-location seemed to have a limited influence, if any, on referral frequency, since 


\section{Nurse referrals}

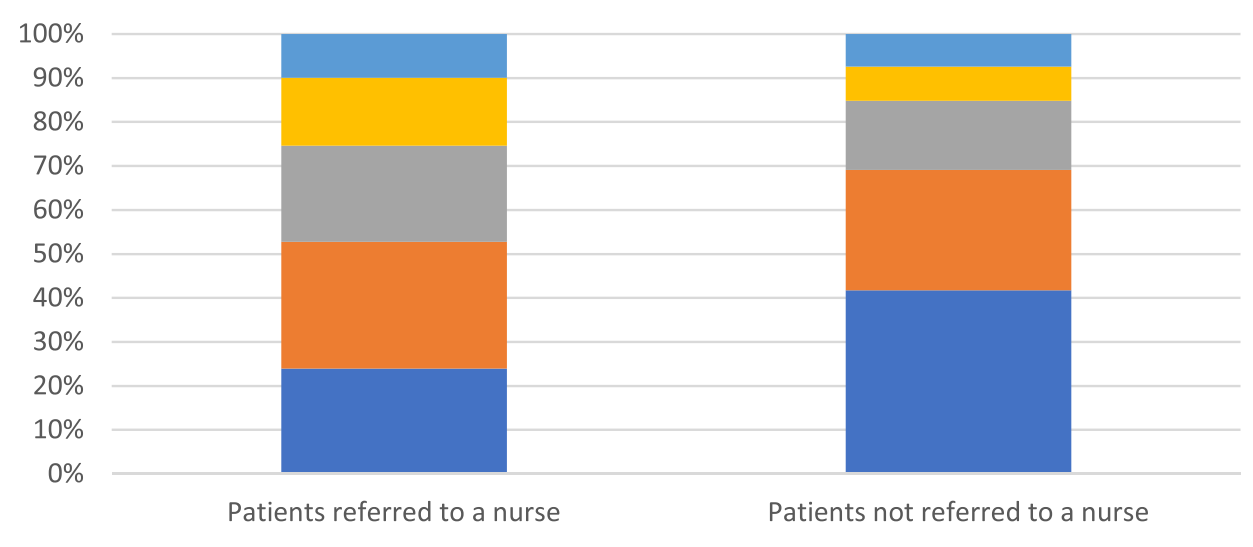

$\square 1 \mathrm{CR} \square 2 \mathrm{CR} \square 3 \mathrm{CR} \square 4 \mathrm{CR} \square 5+\mathrm{CR}$

\section{Physiotherapist referrals}

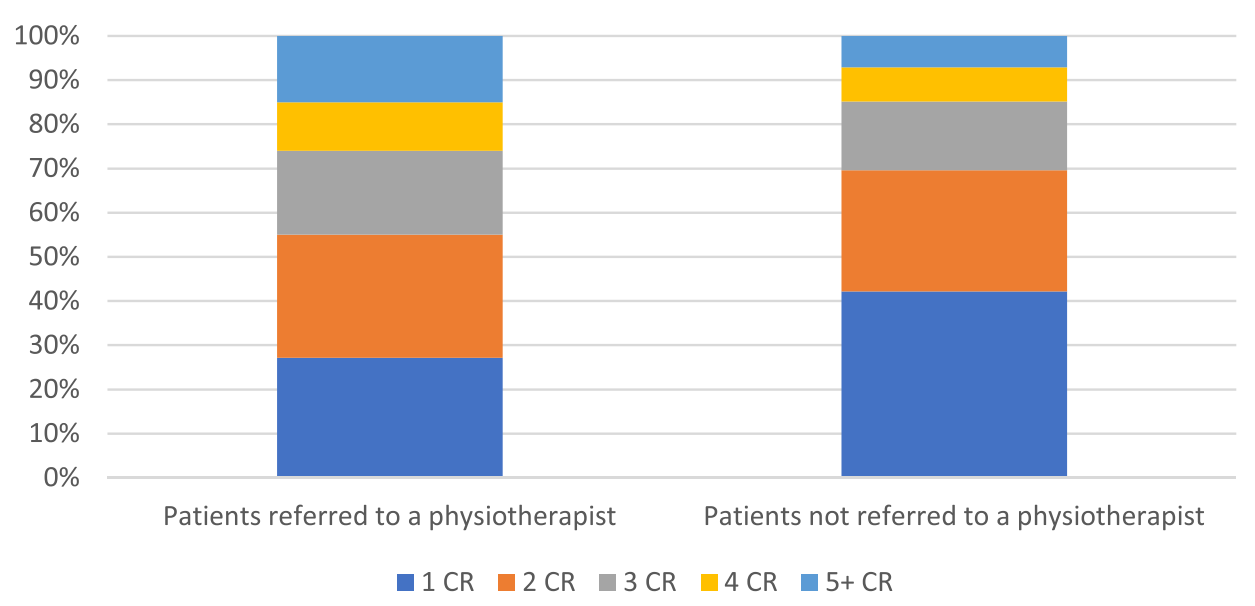

\section{Podiatrist referrals}

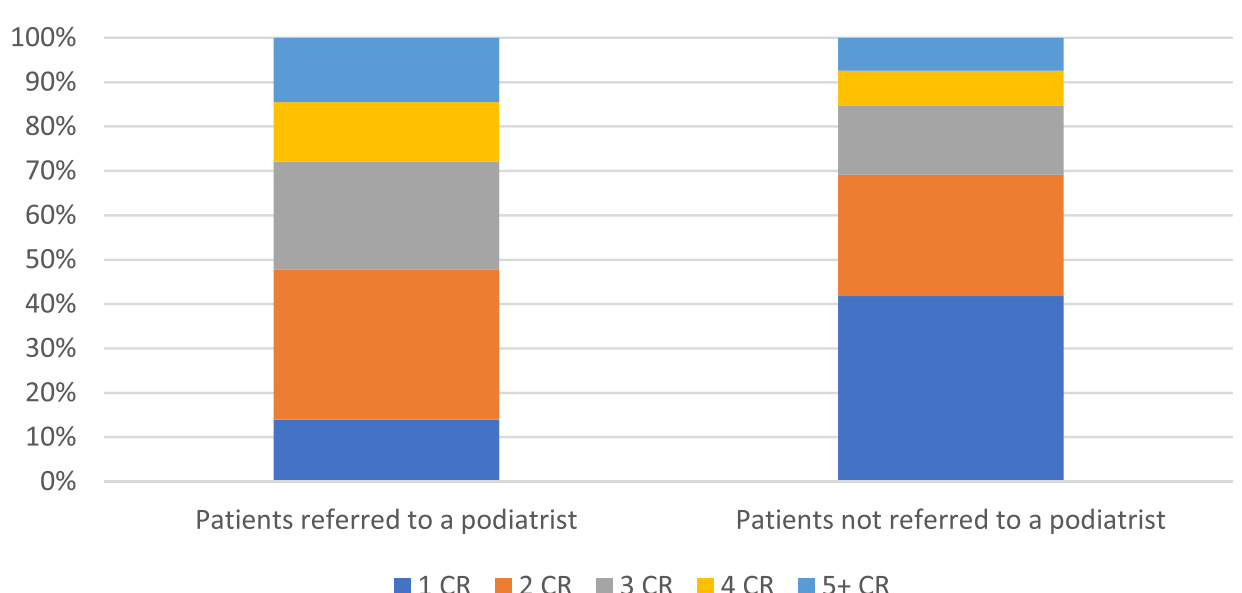

Fig. 2 Significant positive association between number of consultation results (CR) and nurse, physiotherapist, and podiatrist referral rates 
only podiatrist referrals were slightly higher in multiprofessional centres versus solo or mono-professional group centres. Overall, patient characteristics and clinical situations impact referral frequency more than GP-related factors suggesting that patients who need referral most are indeed those who are most often referred.

Several authors describe the referral process as a first step in interprofessional collaboration or teamwork [50, 51]. It is therefore important to acknowledge that our study does not enable in-depth analysis of the degree of collaboration, or the conditions required to implement efficient interprofessional practice in primary care. Furthermore, GP practices may not always be aligned with optimal care and observing practice referrals is not sufficient to determine what their referral frequency should be. However, improved understanding of the frequency and factors associated with GP referral to NPHPs provides useful information for health policy development support including planning for future healthcare workforce requirements and implementing interprofessional teams in primary care.

Although the ECOGEN study is slightly dated, to our knowledge, it is the only study which has reported data on NPHP referrals in France and equivalent data do not exist for other countries. Study sample size is large with 128 GPs and 20,613 patient consultations. Included GPs were representative of French GPs in terms of age, gender, practice location and annual consultation numbers $[17,26]$. However, all participating GPs were GP internship supervisors. Compared with other GPs, they have similar continuing professional development participation rates, and their patient characteristics don't differ, but they more often work in group practice and have shorter weekly working hours. The potential impact of these differences on our results is difficult to appreciate. Furthermore, the proportion of female GPs has increased steadily since the ECOGEN study was performed and was $44.2 \%$ in 2019 [data upon request from French health insurance (CNAMTS)] versus $34 \%$ in the ECOGEN study, which may slightly influence referral frequencies.

Data collection completeness was excellent since most patients consented to participate (only $0.8 \%(n=168)$ of consultations were not included due to lack of consent). Data entry was reliable as no significant difference was observed between the $4.7 \%$ double recorded consultations (mean difference: $0.002 ; p=0.69$ ) [17].

However, study design introduces an information bias, as only new and explicit referrals were considered in the data collection. This may underestimate referral rates, especially for nurses, where prescriptions are commonly written for several months. Furthermore, the factors associated with referral rates are based on univariate statistical analysis since this study aimed to describe GP practice from an organisational perspective. Modelling patient referral probability with a more clinical perspective would require multivariate analyses.

Beyond the general observation suggesting that national health system characteristics may be a strong determinant for NPHP referrals, our data are specific to France and applicability to other settings is not possible without caution. Should data from other countries become available, it would be interesting to compare them with the ECOGEN data and determine the similarities or differences according to health care system organisation, including NPHP reimbursement. Future investigations should also explore the implications of receiving care from different health professionals, according to specific situations and needs, as well as implications for providers who are potentially filling in for specialist care due to limited accessibility. Finally, future research should address modalities of interprofessional collaboration and teamwork rather than just referrals.

\section{Conclusions}

In France, GPs refer around 1 out of 15 patients (6.8\%) to NPHPs. Referral frequency is associated with patient characteristics and clinical situations more than GPrelated factors, suggesting that patients needing referral most are most often referred. Physiotherapists, podiatrists, and nurses are the most common referrals because the French national health insurance only reimburses treatment costs for these three NPHPs upon GPs referral. Health system legislation and NPHP reimbursement appear to be strong determinants for NPHP referrals. This means there is room for change if health policies aim to support multiprofessional care development.

\section{Abbreviations \\ GP: General practitioner; NPHP: Non-physician health professional; ICPC-2: International Classification of Primary Care, 2nd edition. \\ Acknowledgements \\ We would like to warmly thank all patients, trainees and GP supervisors who accepted to participate in the ECOGEN study, as well as the ECOGEN scientific committee, especially Prof. Laurent Letrilliart and Alain Mercier, and the French National College of teaching GPs. \\ This article (English correction and formatting of the manuscript) was supported by the French network of University Hospitals HUGO (Hôpitaux Universitaires du Grand Ouest.) \\ Editorial assistance in the preparation of this article was provided by Speak the Speech Consulting.}

\section{Authors' contributions}

$C A, C B$ and $A R R$ agreed on study objectives and protocol. MP, CB, CA and ARR recoded and analysed data. $M P, M C, G T L, C A, W B, C B$ and $A R R$ interpreted and discussed results. All authors read and approved the final manuscript. 


\section{Authors' information}

MP, MC, GTL, CA, WB, CB and ARR are practicing GPs and members of the Department of General Practice, University of Angers.

\section{Funding}

This research received no specific grant from any funding agency in the public, commercial or not-for-profit sectors.

\section{Availability of data and materials}

The datasets analysed during the current study are available from the corresponding author on reasonable request.

\section{Declarations}

\section{Ethics approval and consent to participate}

A flyer in the GP waiting room informed patients about the study. GPs presented the study to patients at the beginning of the consultation and obtained their written informed consent. The ECOGEN study was declared to the French competent authorities: Comité consultatif sur le traitement de I'information en matière de recherche dans le domaine de la santé (CCTIRS, $n^{\circ} 11605$ ), Commission nationale de l'informatique et des libertés (CNIL, $n^{\circ}$ 1549782). An ethics committee approved the ECOGEN study (CPP Sud-Est IV, registration number: L11-149, approval date: 10/11/2011) and included consent for ancillary studies on the ECOGEN database.

\section{Consent for publication}

Not applicable.

\section{Competing interests}

The authors report no competing interest.

\section{Author details}

${ }^{1}$ Département de médecine générale, Univ Angers, F-49000 Angers, France. ${ }^{2}$ Univ Angers, Univ Rennes, EHESP, Inserm, IRSET-ESTER, SFR ICAT, F-49000 Angers, France. ${ }^{3}$ Département de médecine de famille et de médecine d'urgence, Université de Sherbrooke, Québec, Canada.

Received: 25 June 2021 Accepted: 3 November 2021

Published online: 05 January 2022

\section{References}

1. Belche JL, Berrewaerts MA, Ketterer F, Henrard G, Vanmeerbeek M, Giet D. From chronic disease to multimorbidity: which impact on organization of health care. Presse Med. 2015;44(11):1146-54.

2. Busse R, Blumel M, Scheller-Kreinsen D, Zentner A. Tackling chronic disease in Europe; strategies, interventions and challenges. Copenhagen: European Observatory on Health Systems and Policies; 2010.

3. Mousques J. Soins primaires et performance : de la variabilité des pratiques des médecins généralistes au rôle de l'organisation des soins. Paris: Paris-Dauphine University; 2014

4. Green LA, Fryer GE Jr, Yawn BP, Lanier D, Dovey SM. The ecology of medical care revisited. N Engl J Med. 2001;344(26):2021-5.

5. Atun R. What are the advantages and disadvantages of restructuring a health care system to be more focused on primary care services? Copenhagen: WHO Regional Office for Europe (Health Evidence Network Report); 2004

6. Willcox S, Lewis G, Burgers J. Strengthening primary care: recent reforms and achievements in Australia, England, and the Netherlands. Issue Brief (Commonw Fund). 2011;27:1-19.

7. OECD, Union E. Health at a glance: Europe 2016. 2016.

8. LOI n $2019-774$ du 24 juillet 2019 relative à l'organisation et à la transformation du système de santé, France. Available at: https://www.legifrance. gouv.fr/jorf/id/JORFTEXT000038821260 [Accessed 22 Nov 2021]

9. Gilbert JH, Yan J, Hoffman SJ. A WHO report: framework for action on interprofessional education and collaborative practice. J Allied Health. 2010;39(Suppl 1):196-7.

10. Cartier T, Mercier A, Pouvourville N, et al. Constats sur l'organisation des soins primaires en France [French healthcare system organisation: review]. Exercer La Revue Francaise de Medecine Generale. 2012;23(101):65-71

11. Sripa P, Hayhoe B, Garg P, Majeed A, Greenfield G. Impact of GP gatekeeping on quality of care, and health outcomes, use, and expenditure: a systematic review. Br J Gen Pract. 2019;69(682):e294-303.

12. Davies P, Pool R, Smelt G. What do we actually know about the referral process? Br J Gen Pract. 2011;61(593):752-3.

13. Otters H, van der Wouden JC, Schellevis FG, van Suijlekom-Smit LW, Koes BW. Dutch general practitioners' referral of children to specialists: a comparison between 1987 and 2001. Br J Gen Pract. 2004;54(508):848-52.

14. Rosemann $T$, Wensing M, Rueter $G$, Szecsenyi J. Referrals from general practice to consultants in Germany: if the GP is the initiator, patients' experiences are more positive. BMC Health Serv Res. 2006;6:5.

15. van Dijk CE, de Jong JD, Verheij RA, Jansen T, Korevaar JC, de Bakker $\mathrm{DH}$. Compliance with referrals to medical specialist care: patient and general practice determinants: a cross-sectional study. BMC Fam Pract. 2016;17:11.

16. Loussouarn C, Franc $C$, Videau Y, Mousquès J. Impact de l'expérimentation de coopération entre médecin généraliste et infirmière Asalée sur I'activité des médecins. Paris: Irdes; 2019.

17. Letrilliart L, Supper I, Schuers M, et al. The ECOGEN study: elements of the consultation in general practice. Exercer. 2014;114:148-57.

18. Bourgueil Y, Ramond-Roquin A, Schweyer F-X. Les soins primaires en question(s). Rennes: Presses de l'EHESP; 2021.

19. Fund.; TC. International profiles of health care systems. 2020. Available from: https://www.commonwealthfund.org/international-health-policycenter/system-profiles.

20. Bourgueil $Y$, Marek A. Three models of primary care organisation in Europe, Canada, Australia and New-Zealand; 2009. p. 141.

21. Verbeke M, Schrans D, Deroose S, De Maeseneer J. The international classification of primary care (ICPC-2): an essential tool in the EPR of the GP. Stud Health Technol Inform. 2006;124:809-14.

22. Hofmans-Okkes IM, Lamberts $H$. The international classification of primary care (ICPC): new applications in research and computer-based patient records in family practice. Fam Pract. 1996;13(3):294-302.

23. WHO. International classification of primary care, 2 nd edition (ICPC-2). Available from: https://www.who.int/standards/classifications/other-class ifications/international-classification-of-primary-care. Accessed 22 Nov 2021.

24. Cohen MM, Penman S, Pirotta M, Da Costa C. The integration of complementary therapies in Australian general practice: results of a national survey. J Altern Complement Med. 2005;11(6):995-1004.

25. Mulquiney KJ, Tapley A, van Driel ML, Morgan S, Davey AR, Henderson KM, et al. Referrals to dietitians/nutritionists: a cross-sectional analysis of Australian GP registrars' clinical practice. Nutr Diet. 2018;75(1):98-105.

26. Hsiung L, Supper I, Guérin M, et al. Health care procedures in general practice: data analysis from the national ECOGEN study. Exercer. 2014;114:162-9.

27. Siopis G, Jones A, Allman-Farinelli M. The dietetic workforce distribution geographic atlas provides insight into the inequitable access for dietetic services for people with type 2 diabetes in Australia. Nutr Diet. 2020;77(1):121-30.

28. Kayrouz R, Dear BF, Karin E, Fogliati VJ, Gandy M, Keyrouz L, et al. Acceptability of mental health services for anxiety and depression in an Arab sample. Community Ment Health J. 2018;54(6):875-83.

29. Gellert P, Lech S, Kessler EM, Herrmann W, Döpfmer S, Balke K, et al. Perceived need for treatment and non-utilization of outpatient psychotherapy in old age: two cohorts of a nationwide survey. BMC Health Serv Res. 2021;21(1):442.

30. Forhan M, Risdon C, Solomon P. Contributors to patient engagement in primary health care: perceptions of patients with obesity. Prim Health Care Res Dev. 2013;14(4):367-72.

31. Buxton BK, Snethen J. Obese women's perceptions and experiences of healthcare and primary care providers: a phenomenological study. Nurs Res. 2013;62(4):252-9.

32. King M, Nazareth I, Levy G, Walker C, Morris R, Weich S, et al. Prevalence of common mental disorders in general practice attendees across Europe. Br J Psychiatry. 2008;192(5):362-7.

33. Roca M, Gili M, Garcia-Garcia M, Salva J, Vives M, Garcia Campayo J, et al. Prevalence and comorbidity of common mental disorders in primary care. J Affect Disord. 2009;119(1-3):52-8. 
34. Nicholas $L$, Roberts DC, Pond D. The role of the general practitioner and the dietitian in patient nutrition management. Asia Pac J Clin Nutr. 2003;12(1):3-8.

35. Schers $H$, Bor $H$, van den Hoogen $H$, van Weel C. What went and what came? Morbidity trends in general practice from the Netherlands. Eur J Gen Pract. 2008;14(Suppl 1):13-24.

36. Mitchell $L$, Ball LE, Ross $L J$, Barnes KA, Williams LT. Effectiveness of dietetic consultations in primary health care: a systematic review of randomized controlled trials. J Acad Nutr Diet. 2017:117(12):1941-62.

37. Dobbins MI, Thomas SA, Melton SL, Lee S. Integrated care and the evolution of the multidisciplinary team. Prim Care. 2016;43(2):177-90.

38. Bourgueil Y, Le Fur P, Mousques J, Yilmaz E. La coopération médecins généralistes/infirmières améliore le suivi des patients diabétiques de type 2; Principaux résultats de l'expérimentation ASALEE: IRDES; 2008. Available from: https://www.irdes.fr/Publications/Qes/Qes136.pdf

39. Fournier C, Bourgeois I, Naiditch M. Doctor-nurse cooperation through ASALEE (Team Health Project in Private Practice): a space where primary care practices are being transformed: IRDES; 2018. Available from: https:// www.irdes.fr/english/issues-in-health-economics/232-doctor-nursecooperation-through-asalee.pdf

40. Hudson CC, Gauvin S, Tabanfar R, Poffenroth AM, Lee JS, O'Riordan AL. Promotion of role clarification in the health care team challenge. J Interprof Care. 2017;31(3):401-3.

41. Medicine Io. In: Olson S, editor. Allied health workforce and services: workshop summary. Washington, DC: The National Academies Press; 2011. p. 96.

42. Fortin M, Bravo G, Hudon C, Vanasse A, Lapointe L. Prevalence of multimorbidity among adults seen in family practice. Ann Fam Med. 2005;3(3):223-8.

43. WHO. Ageing and health: key facts. 2018 [updated 5 February 2018]. Available from: https://www.who.int/news-room/fact-sheets/detail/ ageing-and-health.

44. Wallace E, Salisbury C, Guthrie B, Lewis C, Fahey T, Smith SM. Managing patients with multimorbidity in primary care. BMJ. 2015;350:h176.

45. Rijken M, Struckmann V, van der Heide I, Hujala A, Barbabella F, van Ginneken $\mathrm{E}$, et al. Health systems and policy analysis - how to improve care for people with multimorbidity in Europe? Berlin: ICARE4EU Consortium; 2016.

46. Frogner BK, Harwood K, Andrilla CHA, Schwartz M, Pines JM. Physical therapy as the first point of care to treat low back pain: an instrumental variables approach to estimate impact on opioid prescription, health care utilization, and costs. Health Serv Res. 2018:53(6):4629-46.

47. Franks $P$, Bertakis KD. Physician gender, patient gender, and primary care. J Women's Health (Larchmt). 2003;12(1):73-80.

48. Liddle J, Clemson L, Mackenzie L, Lovarini M, Tan A, Pit SW, et al. Influences on general practitioner referral to allied health professionals for fall prevention in primary care. Australas J Ageing. 2020;39(1):e32-e9.

49. Chan BC, Perkins D, Wan Q, Zwar N, Daniel C, Crookes P, et al. Finding common ground? Evaluating an intervention to improve teamwork among primary health-care professionals. Int J Qual Health Care. 2010;22(6):519-24.

50. Lessard L, Morin D, Sylvain H. Understanding teams and teamwork. Can Nurse. 2008;104(3):12-3

51. Careau E. Processus de collaboration interprofessionnelle en santé et services sociaux; proposition d'une grille d'observation des rencontres d'équipe interdisciplinaires. Quebec: Laval University; 2013.

\section{Publisher's Note}

Springer Nature remains neutral with regard to jurisdictional claims in published maps and institutional affiliations.

Ready to submit your research? Choose BMC and benefit from:

- fast, convenient online submission

- thorough peer review by experienced researchers in your field

- rapid publication on acceptance

- support for research data, including large and complex data types

- gold Open Access which fosters wider collaboration and increased citations

- maximum visibility for your research: over $100 \mathrm{M}$ website views per year

At BMC, research is always in progress.

Learn more biomedcentral.com/submissions 